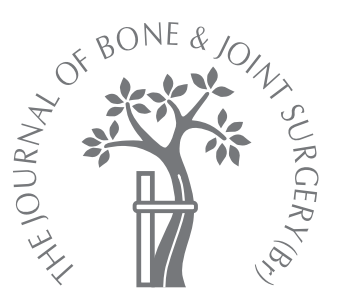

S. Rajasekaran,

J. Naresh Babu,

J. Dheenadhayalan,

A. P. Shetty,

S. R. Sundararajan,

M. Kumar,

S. Rajasabapathy

From Ganga

Hospital,

Coimbatore, India

- S. Rajasekaran, MS (Ortho), DNB (Ortho), FRCS (Ed),

MChOrth (Liverpool), PhD,

Director \& Head of

Orthopaedics and Spine

Surgery

J. Naresh Babu, MS (Ortho),

FNB, Trauma Fellow

II. Dheenadhayalan, MS

(Ortho), Consultant in Trauma

Surgery

A. P. Shetty, MS (Ortho), DNB

(Ortho), Consultant

Orthopaedic Surgeon

- S. R. Sundararajan, MS

(Ortho), Consultant

Orthopaedic Surgeon

M. Kumar, MS (Ortho),

Trauma Fellow

S. Rajasabapathy, MS, MCh

FRCS, DNB, Director and Head

of Plastic and Reconstructive

Microsurgery

Department of Orthopaedics

Ganga Hospital, Ramnagar,

Coimbatore 641009, India.

Correspondence should be sent to Dr S. Rajasekaran; e-mail: sr@gangahospital.com

(C)2006 British Editorial Society of Bone and Joint Surgery doi:10.1302/0301-620X.88B10. $17631 \$ 2.00$

$J$ Bone Joint Surg [Br]

2006;88-B:1351-60.

Received 10 January 2006;

Accepted after revision 18 May 2006

\title{
A score for predicting salvage and outcome in Gustilo type-IIIA and type-IIIB open tibial fractures
}

Limb-injury severity scores are designed to assess orthopaedic and vascular injuries. In Gustilo type-IIIA and type-IIIB injuries they have poor sensitivity and specificity to predict salvage or outcome.

We have designed a trauma score to grade the severity of injury to the covering tissues, the bones and the functional tissues, grading the three components from one to five. Seven comorbid conditions known to influence the management and prognosis have been given a score of two each. The score was validated in 109 consecutive open injuries of the tibia, 42 type-IIIA and 67 type-IIIB. The total score was used to assess the possibilities of salvage and the outcome was measured by dividing the injuries into four groups according to their scores as follows: group I scored less than 5, group II 6 to 10, group III 11 to 15 and group IV 16 or more.

A score of $\mathbf{1 4}$ to indicate amputation had the highest sensitivity and specificity. Our trauma score compared favourably with the Mangled Extremity Severity score in sensitivity $(98 \%$ and $99 \%)$, specificity $(100 \%$ and $17 \%)$, positive predictive value $(100 \%$ and $97.5 \%)$ and negative predictive value $(70 \%$ and $50 \%)$, respectively. A receiver-operating characteristic curve constructed for 67 type-IIIB injuries to assess the efficiency of the scores to predict salvage, showed that the area under the curve for this score was better $(0.988( \pm 0.013 \mathrm{SEM}))$ than the Mangled Extremity Severity score (0.938 ( \pm 0.039 SEM)). All limbs in group IV and one in group III underwent amputation. Of the salvaged limbs, there was a significant difference in the three groups for the requirement of a flap for wound cover, the time to union, the number of surgical procedures required, the total days as an in-patient and the incidence of deep infection ( $p<\mathbf{0 . 0 0 1}$ for all). The individual scores for covering and functional tissues were also found to offer specific guidelines in the management of these complex injuries.

The scoring system was found to be simple in application and reliable in prognosis for both limb-salvage and outcome measures in type-IIIA and type-IIIB open injuries of the tibia.

The Gustilo-Anderson classification ${ }^{1,2}$ is the most widely used means of assessing open injuries, but it has many limitations. ${ }^{3}$ Following the original classification; the type-III injuries were further divided into type-IIIA to describe adequate soft-tissue cover of the fracture despite extensive skin loss, type-IIIB which denoted extensive soft-tissue loss, periosteal stripping and exposure of bone, and type-IIIC which described an open fracture with an associated arterial injury requiring repair. ${ }^{3}$ The definition has since undergone many modifications and there is no uniformity in its description worldwide. ${ }^{4-7}$ Type-IIIB injuries, which are the most challenging, have a wide spectrum. No guidelines can be drawn using the classification for either management or prog- nosis (Fig. 1). In type-IIIB injuries the skin, muscles, nerves and bones are injured to varying degrees. Although the classification focuses mainly on the soft-tissue injury, ${ }^{4-6}$ the extent of the damage to the muscles and bones may be under-represented and of such severity that it influences the final outcome (Fig. 2). The classification is subjective and the inter-observer agreement is also only moderate to poor, highly case-dependent and varies with the experience of the surgeon. ${ }^{8,9}$ There is a growing opinion that this classification is not an adequate basis for making decisions for treatment or for comparing published results. . $^{3,11}$

The classification does not address the question of salvage, but reconstruction of a severe type-IIIB injury can be challenging. The many 

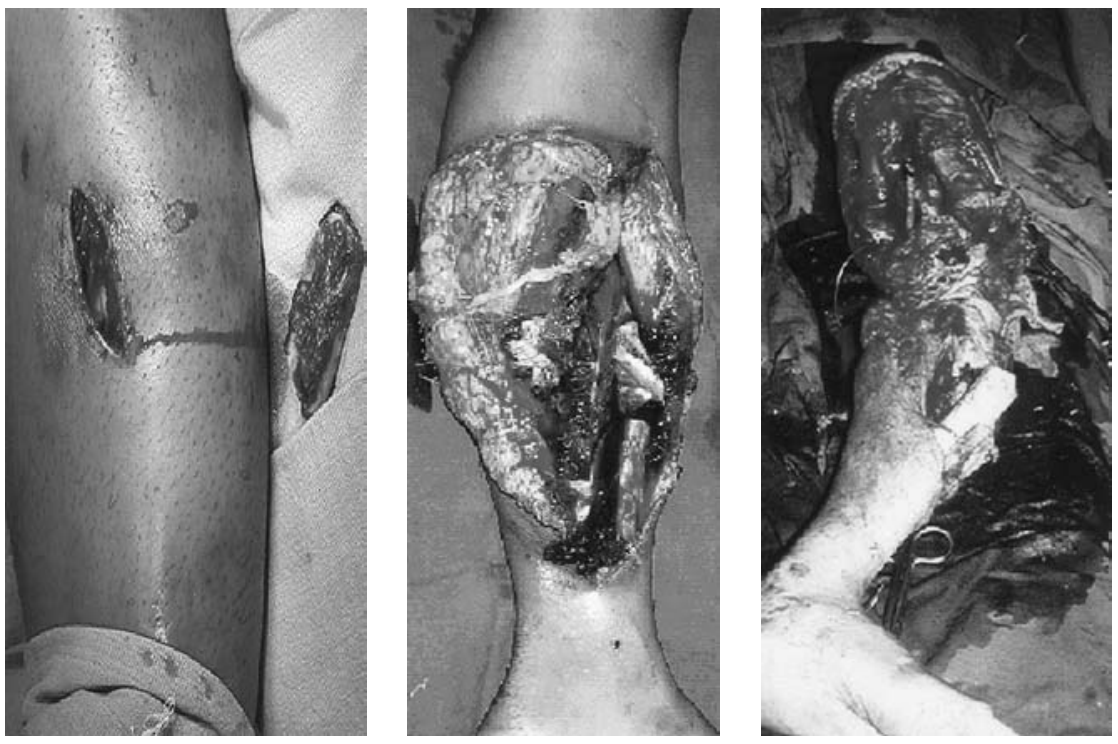

Fig. 1

Photographs of three injuries which are by definition Gustilo-Anderson type-IIIB. The management and prognosis for the three injuries are completely different.

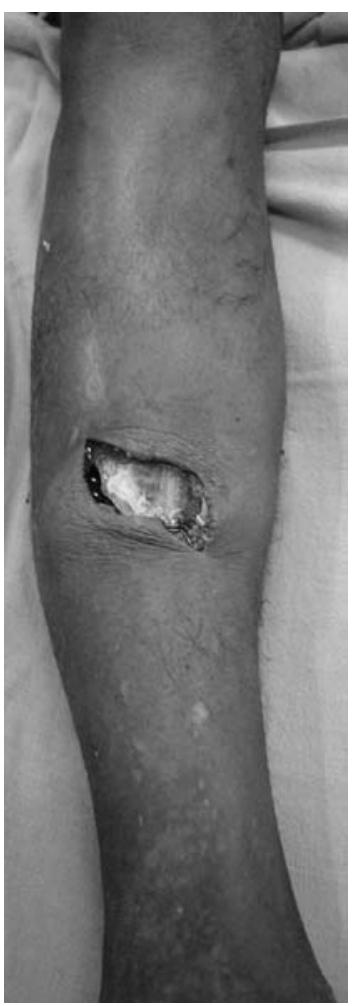

Fig. 2a

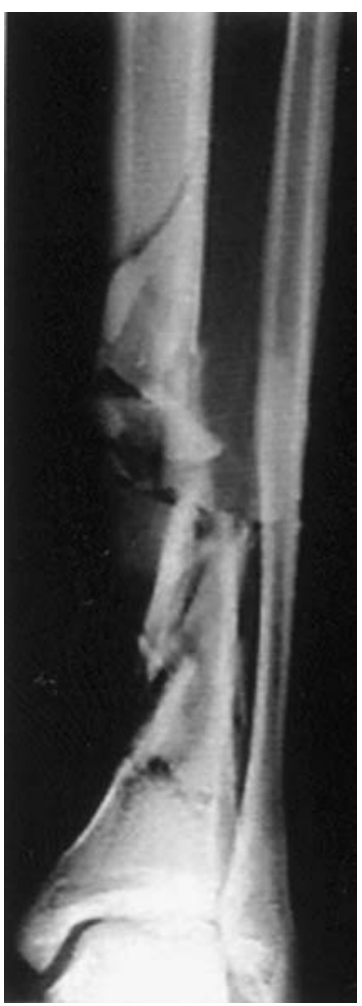

Fig. $2 b$

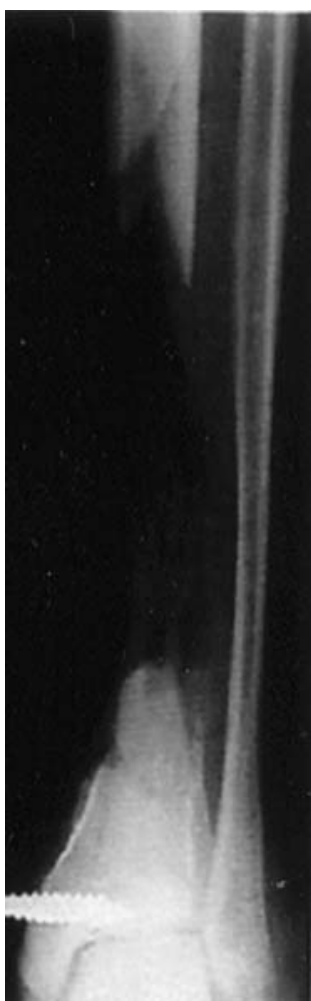

Fig. $2 c$
Photograph (a) and radiographs ( $b$ and $c$ ) showing that the complexity and duration of treatment of type-IIIB injuries depends not only on the severity of the soft-tissue injury but also on that of the bone injury. In this case there was severe comminution and a large bone defect after debridement. The challenge in treatment will be to achieve bony union rather than soft-tissue cover. scoring systems ${ }^{12-17}$ available have been designed to assess limbs with combined orthopaedic and vascular injuries and have a low potential for prediction of amputation in typeIIIB injuries. ${ }^{18}$ We therefore felt the need to develop a single scoring system which was simple to use, had high inter- observer reliability, a high sensitivity and specificity for salvage and was able to predict the potential number of inpatient days, the requirement for a flap, the number of secondary procedures which would be required and the rate of infection. 
Table I. The Ganga Hospital injury severity score

\begin{tabular}{|c|c|}
\hline & Score \\
\hline \multicolumn{2}{|l|}{ Covering structures: skin and fascia } \\
\hline \multicolumn{2}{|l|}{ Wounds without skin loss } \\
\hline Not over the fracture & 1 \\
\hline Exposing the fracture & 2 \\
\hline \multicolumn{2}{|l|}{ Wounds with skin loss } \\
\hline Not over the fracture & 3 \\
\hline Over the fracture & 4 \\
\hline Circumferential wound with skin loss & 5 \\
\hline \multicolumn{2}{|l|}{ Skeletal structures: bone and joints } \\
\hline $\begin{array}{l}\text { Transverse/oblique fracture/ butterfly fragment }<50 \% \\
\text { circumference }\end{array}$ & 1 \\
\hline Large butterfly fragment $>50 \%$ circumference & 2 \\
\hline Comminution/segmental fractures without bone loss & 3 \\
\hline Bone loss $<4 \mathrm{~cm}$ & 4 \\
\hline Bone loss $>4 \mathrm{~cm}$ & 5 \\
\hline \multicolumn{2}{|l|}{ Functional tissues: musculotendinous (MT) and nerve units } \\
\hline Partial injury to MT unit & 1 \\
\hline Complete but repairable injury to MT units & 2 \\
\hline $\begin{array}{l}\text { Irreparable injury to MT units/partial loss of a compartment/ } \\
\text { complete injury to posterior tibial nerve }\end{array}$ & 3 \\
\hline Loss of one compartment of MT units & 4 \\
\hline Loss of two or more compartments/subtotal amputation & 5 \\
\hline \multicolumn{2}{|l|}{ Co-morbid conditions: add 2 points for each condition present } \\
\hline \multicolumn{2}{|l|}{ Injury - debridement interval > 12 hours } \\
\hline \multicolumn{2}{|l|}{ Sewage or organic contamination/farmyard injuries } \\
\hline \multicolumn{2}{|l|}{ Age $>65$ years } \\
\hline \multicolumn{2}{|l|}{$\begin{array}{l}\text { Drug-dependent diabetes mellitus/cardiorespiratory diseases } \\
\text { leading to increased anaesthetic risk }\end{array}$} \\
\hline \multicolumn{2}{|l|}{$\begin{array}{l}\text { Polytrauma involving chest or abdomen with injury severity } \\
\text { score }>25 / \text { fat embolism }\end{array}$} \\
\hline \multicolumn{2}{|l|}{$\begin{array}{l}\text { Hypotension with systolic blood pressure }<90 \mathrm{mmHg} \text { at } \\
\text { presentation }\end{array}$} \\
\hline Another major injury to the same limb/compartment syndrom & \\
\hline
\end{tabular}

\section{Patients and Methods}

The study was performed in a tertiary trauma reference centre where more than 300 open injuries of the lower limbs are treated every year. It serves a population of five million people and approximately $50 \%$ of the referred injuries are type-IIIB. Of the 554 patients with open fractures admitted between February 1999 and February 2001, 241 had open tibial injuries. Of these 42 had a type-IIIA and 67 type-IIIB injury and were followed up for a mean of 43 months (36 to 60). There were 107 males and two females with a mean age of 34.97 years (6 to 73 ). The cause of injury was a road-traffic accident in 87 , an industrial accident in 11, a fall from a height in eight and farmyard injuries in three. In 56 patients there were comorbid conditions, one only in 41, two in 12 and three in three.

The design of the Ganga hospital score. The score was developed in 1994 and modified to its present form after three clinical trials. One to five points are allocated, according to the severity of injury, to each of the three components of the limb: the covering tissues (skin and fascia), the skeleton (bones and joints) and the functional tissues (muscles, tendons and nerve units). Systemic factors which may influence treatment and outcome are given two points each and the final score is arrived at by adding the individual scores together (Table I). A score of one or two for any tissue indicates that no special secondary procedures will be required and the ultimate outcome will not be influenced adversely. A score of three shows that some special procedure will be required for healing of that tissue, but that a good functional outcome can be achieved with appropriate management. A score of four and above indicates that the injury will require many operations, a prolonged stay in hospital, expensive treatment, and could end with a poor functional outcome.

Covering tissues (skin and fascia) (Fig. 3). Wounds without skin loss which have an adequate soft-tissue bed and can be approximated without tension after debridement are given a score of one if they do not overlie the fracture and two if they expose it. Wounds with primary skin loss or which require extensive debridement of the skin due to friction burns or degloving have a score of three if they are not over the fracture site and four if they expose it. Wounds involving skin loss over the entire circumference of the limb have a score of five.

Skeletal structures (bone and joints). Transverse or oblique fractures or a butterfly fragment involving less than $50 \%$ of the circumference have a score of one. The presence of a large butterfly fragment involving more than $50 \%$ of the circumference indicates a score of two and extensive comminution or segmental fractures without loss of bone a score three. Primary or secondary loss of bone of less than $4 \mathrm{~cm}$ has a score of four and of more than $4 \mathrm{~cm}$ a score of five.

Functional tissues (muscles, tendons and nerve units) (Fig. 4). Exposure of musculotendinous units of any size with only partial direct damage of muscle units has a score of one, a complete but repairable injury with no resultant loss of function a score of two, and irreparable injury resulting in partial loss of a compartment or a complete injury to the posterior tibial nerve has a score of three. Extensive damage of one entire compartment has a score of four and loss of more than one compartment a score of five.

Comorbid factors. Factors which have a negative influence on the management, either by increasing the anaesthetic risk for major surgical procedures or the outcome in open injuries, are each given a score of two (Table I). An interval of more than 12 hours before debridement of the injury, farmyard injuries or sewage or organic contamination, age above 65 years, drug-dependent diabetes mellitus, the presence of cardiorespiratory diseases leading to an increased anaesthetic risk, polytrauma involving chest and abdominal injuries with an Injury Severity Score ${ }^{19}>25$, fat embolism, hypotension with a systolic pressure of less than 90 $\mathrm{mmHg}$ at presentation, a compartment syndrome or another major injury to the same limb are each given a score of two and the final score computed.

The scoring is assessed after debridement when the severity of injury to all components of the limb has been established accurately. 


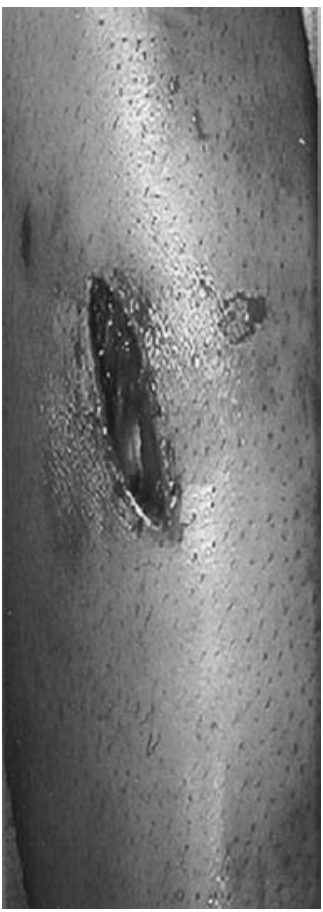

Fig. 3a

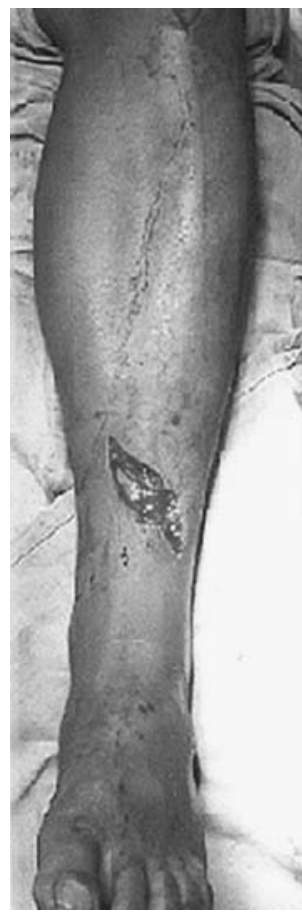

Fig. 3b

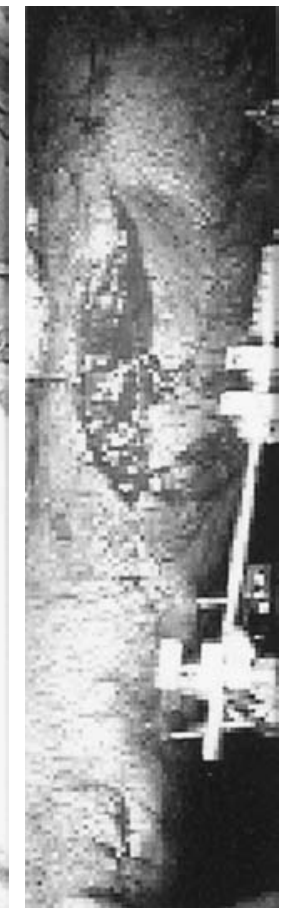

Fig. 3c

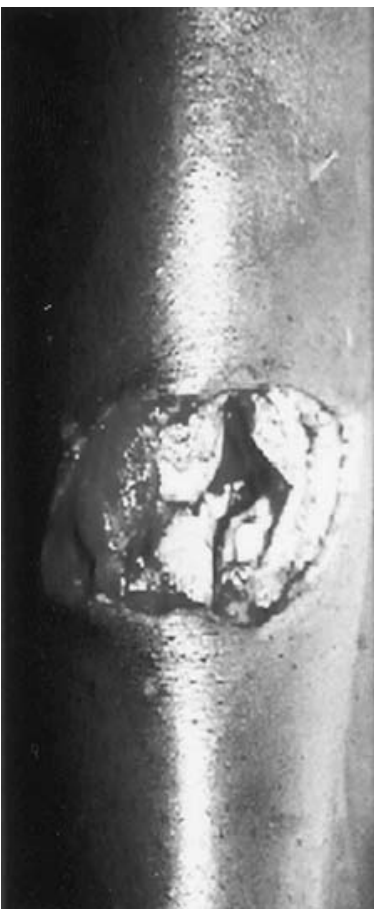

Fig. 3d

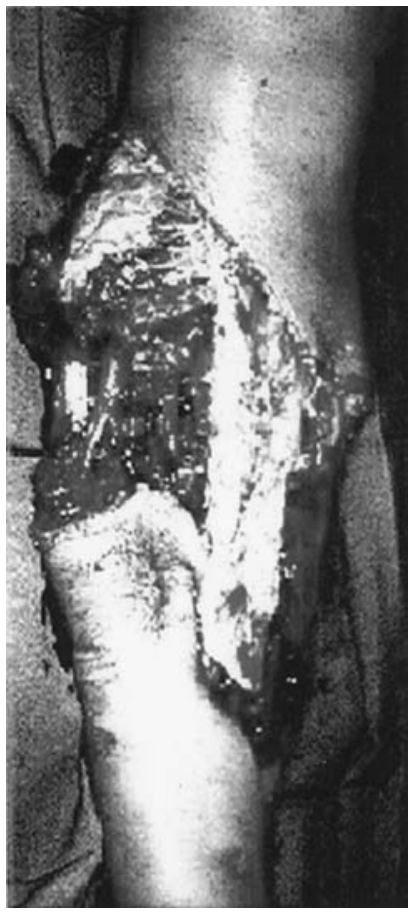

Fig. 3e

Scoring for covering tissues. Photographs showing a) score 1, wound without skin loss and not over the site of the fracture, b) score 2, wound without skin loss but exposing the fracture site, c) score 3, wound with skin loss and not over the fracture site, d) score 4, wound with skin loss and over the fracture site and e) score 5, circumferential wound with bone circumferentially exposed.

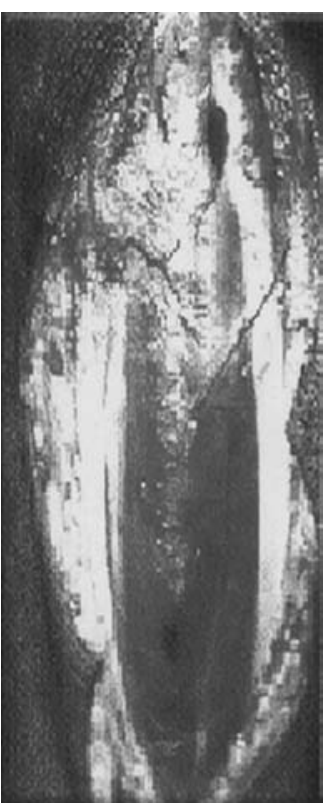

Fig. $4 \mathrm{a}$

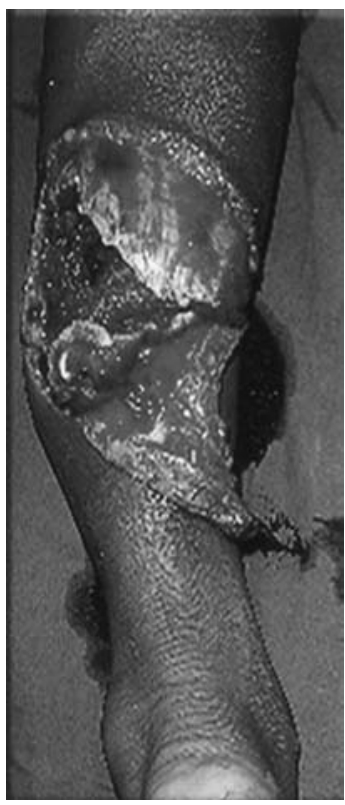

Fig. $4 \mathrm{~b}$

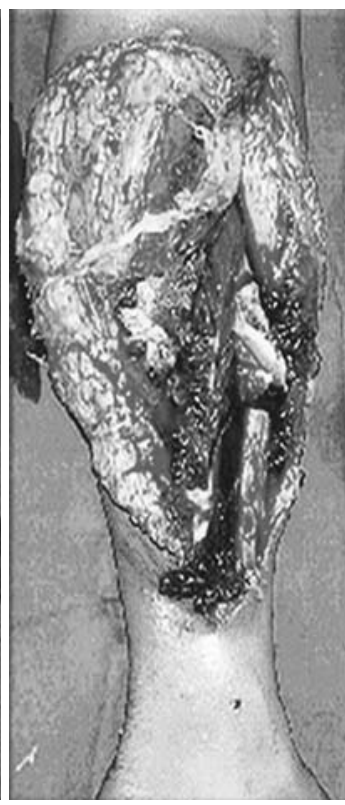

Fig. 4c

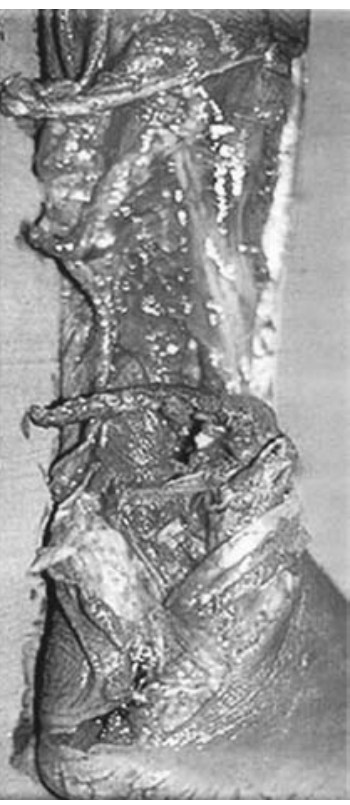

Fig. 4d

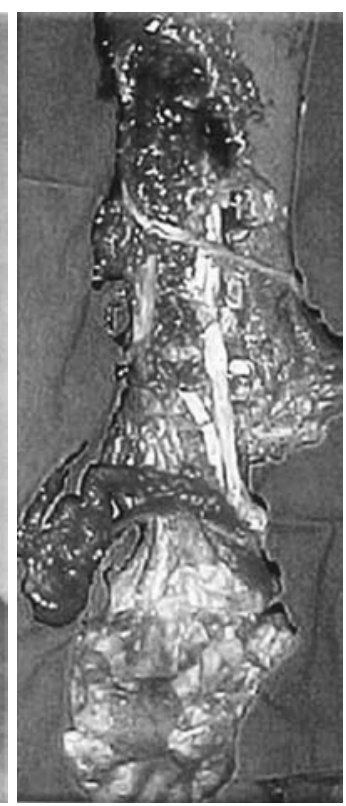

Fig. $4 \mathrm{e}$

Functional tissues score. Photographs showing a) score 1, partial injury to musculotendinous units, b) score 2, complete but repairable injury to musculotendinous units, c) score 3, irreparable injury to musculotendinous units involving one or more muscles in a compartment or complete injury to the posterior tibial nerve, d) score 4, loss of one entire compartment and e) score 5, loss of two or more compartments or subtotal amputation. 
The total score is used to arrive at a threshold for amputation. This score is determined in order to provide a high specificity so that a salvageable limb will never be amputated primarily. Outcome measures such as in-patient days, the number of surgical procedures, the requirement for flaps, time to bony union and the rate of infection are correlated by dividing the injuries into four groups: group I, total score of 5 and below; group II, 6 to 10; group III, 11 to 15 and group IV, 16 and over.

Inclusion and exclusion criteria. All open injuries of the tibia, irrespective of the site of the fracture and the age of the patient, presenting within 24 hours after injury and classifiable as Gustilo type-IIIA or type-IIIB injury were included in the study. Patients who had a debridement or an initial procedure at another hospital, complete traumatic amputations, a vascular injury requiring a vascular reconstructive procedure for viability or severe associated injuries to the ankle and foot were excluded.

Statistical analysis. The ability of the Ganga hospital score to predict salvage was compared with the Gustilo classification and Mangled Extremity Severity Score by analysing the sensitivity, specificity, positive predictive value and negative predictive value of each. A Receiver Operating Characteristic (ROC) curve was constructed and the area under the curve was calculated for each of these scores to assess their efficiency to predict salvage.

\section{Results}

The inter-observer agreement was measured by using the intraclass correlation coefficient since it was more reliable and applicable than kappa statistics for data which have both scoring and groupings. ${ }^{20,21} \mathrm{~A}$ total of 25 injuries were rated independently in the operating theatre by six observers; three were surgeons with more than ten years experience and three were resident trainees with less than two years training who were knowledgeable about the scoring system. The intraclass correlation coefficient for the Gustilo classification was only 0.63 compared with 0.95 for the covering tissue score, 0.98 for the functional tissue score, 0.99 for the bone score, 0.99 for the comorbidity score, and 0.97 for the total score and group classification. The differ-
Table II. The Gustilo type-IIIA and type-IIIB injuries were widely scattered among the various groups of the Ganga hospital score (GHS) and the Mangled Extremity Severity score (MESS) indicating that injuries of a wide range of severity were clustered together in the Gustilo grade-III classification

\begin{tabular}{llllll}
\hline & GHS & \multicolumn{3}{l}{ MESS } \\
\cline { 2 - 3 } \cline { 5 - 5 } Gustilo type & Group & $\begin{array}{c}\text { Number } \\
\text { of injuries }\end{array}$ & less than $\mathbf{6}$ & 7 or more \\
\hline IIIA $(\mathrm{n}=42)$ & I & 22 & & \\
& II & 20 & & \\
& III & 0 & & \\
IIIB $(n=67)$ & IV & 0 & 42 & 0 \\
& I & 1 & & \\
& II & 31 & & \\
& III & 29 & & \\
& IV & 6 & 63 & 4 \\
\hline
\end{tabular}

ence between the intraclass correlation coefficient for the Gustilo classification and for the Ganga hospital score was statistically significant $(\mathrm{p}<0.001)$. The Gustilo classification was more dependent on the experience of the rater with the intraclass correlation coefficient falling to only 0.39 among trainees.

Clinical applications. Following debridement in the 109 patients, the injuries were assessed and scored appropriately for the Gustilo classification, the Mangled Extremity Severity score ${ }^{12}$ and the Ganga hospital score by the consultant performing the debridement. The 67 injuries classified as Gustilo type-IIIB were seen to include a wide scatter in both the Ganga hospital score and the Mangled Extremity scores (Table II).

Salvage. The decision to amputate or undertake salvage was taken independently by a consensus of the senior members of the plastic and orthopaedic teams without any bias or consideration of any score. Amputations were defined as primary if they were performed during the initial procedure and secondary if carried out at any time after this. Five patients had a primary amputation and two were delayed until secondary procedures had been undertaken (Table III). Of the seven patients undergoing amputation, only three had a Mangled Extremity Severity score of seven or more. The other four had a score of less than seven, indicat-

Table III. Details of the seven limbs which required amputation, all of which were Gustilo type-IIIB

\begin{tabular}{|c|c|c|c|c|c|c|c|c|}
\hline \multirow[b]{2}{*}{ Case } & \multirow[b]{2}{*}{ Timing of amputation } & \multirow[b]{2}{*}{ Reason for amputation } & \multicolumn{5}{|c|}{ Ganga hospital score } & \multirow[b]{2}{*}{ MESS $^{\dagger}$} \\
\hline & & & Skin & Bone & $\mathrm{MT}^{*}$ unit & $\begin{array}{l}\text { Comorbid } \\
\text { conditions score }\end{array}$ & Total score & \\
\hline 1 & Primary & Crush with bone loss & 5 & 5 & 5 & 2 & 17 & 7 \\
\hline 2 & Primary & Crush with bone loss & 4 & 5 & 5 & 4 & 18 & 6 \\
\hline 3 & Secondary (after 6 days) & $\begin{array}{l}\text { Infection with extensive } \\
\text { myonecrosis }\end{array}$ & 4 & 5 & 5 & 4 & 18 & 7 \\
\hline 4 & Primary & Crush with bone loss & 5 & 5 & 5 & 2 & 17 & 6 \\
\hline 5 & Primary & Crush with bone loss & 4 & 5 & 4 & 2 & 15 & 9 \\
\hline 6 & Secondary (after 14 days) & Flap failure & 5 & 4 & 3 & 6 & 18 & 6 \\
\hline 7 & Primary & Crush with bone loss & 4 & 5 & 5 & 2 & 16 & 5 \\
\hline
\end{tabular}

* MT, musculotendinous

† MESS, Mangled Extremity Severity score 
Table IV. Comparison of the Ganga hospital score (GHS) and the Mangled Extremity Severity score (MESS) in predicting limb salvage

\begin{tabular}{lllll}
\hline $\begin{array}{l}\text { Amputation } \\
\text { threshold }\end{array}$ & Sensitivity (\%) & Specificity (\%) & $\begin{array}{l}\text { Positive predictive } \\
\text { value (\%) }\end{array}$ & $\begin{array}{l}\text { Negative predictive } \\
\text { value (\%) }\end{array}$ \\
\hline GHS & 98 & 100 & 100 & 70 \\
MESS & 99 & 17 & 97.5 & 50 \\
\hline
\end{tabular}

ing the poor specificity of this score for predicting amputation in injuries without a vascular component. All injuries requiring amputation had a Ganga hospital score of more than 14 including the two that had secondary amputation, both of which had a score of 18 .

All the 99 patients with a score of 14 or below on the Ganga hospital score had a salvage procedure. By contrast, only two of the three patients with a score of 15 , one of the two with a score of 16 and none of the five with a score of 17 and above had salvage. As regards the Mangled Extremity Severity score, of the seven patients undergoing amputation, only three had a score of seven or more. One had a score of five and the other three had a score of six. One patient with a score of eight also had salvage.

Both patients who underwent secondary amputation had a Ganga hospital score of 18 and a Mangled Extremity Severity score of six and seven. Amputation was not advised primarily because of the expectation of salvage. One patient had a secondary amputation at one week because of extensive secondary loss of soft tissues and avascularity of muscle. The second patient had failure of a latissimus dorsi free flap along with infection, which prompted an amputation at the end of two weeks. In both, the Ganga hospital score had a better predictive value towards amputation that the Mangled Extremity Severity score.

The sensitivity, specificity, positive predictive value and negative predictive value were calculated for the Ganga hospital score with a threshold score of 14 and for the Mangled Extremity Severity score with a threshold score of seven (Table IV). The sensitivity for the Ganga hospital score and Mangled Extremity Severity scores was $98 \%$ and $99 \%$, the specificity was $100 \%$ and $17 \%$, the positive predictive value was $100 \%$ and $97.5 \%$ and the negative predictive value $70 \%$ and $50 \%$, respectively. When considering salvage, a high specificity is preferable to sensitivity and the Ganga hospital score was found to be better from this aspect than the Mangled Extremity Severity score. The low specificity for the latter score is because of the seven patients who underwent amputation, three had a score of less than seven and another with a score of nine also had successful salvage.

The sensitivity and specificity of the Ganga hospital score for various scores were calculated (Table V). Giving emphasis to specificity over sensitivity an amputation threshold score of 14 was determined so that no limb which could ultimately be salvaged would be amputated unnecessarily. All injuries with a score of 14 and below were salvaged and
Table V. Sensitivity and specificity for various amputation threshold scores of the Ganga hospital score (GHS) in predicting limb salvage ranging from 100\% sensitivity to $100 \%$ specificity

\begin{tabular}{lll}
\hline GHS & Sensitivity (\%) & Specificity (\%) \\
\hline 13 & 92.9 & 100 \\
14 & 98 & 100 \\
15 & 99 & 83.3 \\
16 & 99.5 & 66.7 \\
17 & 99.5 & 33.3 \\
18 & 100 & 0 \\
\hline
\end{tabular}

with 17 and above were amputated. The scores of 15 and 16 constituted a 'grey area' where the decision to amputate called for considerable experience.

A binary logistic regression analysis for salvage was done with amputation as the dependent value and the Mangled Extremity Severity score, the Ganga hospital score total score and the Gustilo type as independent variables. Only the Ganga hospital score significantly influenced amputation ( $\mathrm{p}=0.03)$; the Mangled Extremity Severity score and Gustilo type were non-significant $(\mathrm{p}=0.09$ and $\mathrm{p}=0.9$, respectively).

The ability of the Ganga hospital score to predict limb salvage (as defined by the need for an amputation) was compared with that of the Mangled Extremity Severity score and the Gustilo classification, by constructing ROC curves and calculating the area under these curves. A ROC curve plots the sensitivity of an index by its false-positive fraction (1-specificity) over the entire range of possible scores. $^{22}$ The sensitivity/specificity pair for any particular decision threshold is represented by a point on the curve and the performance of the score over the entire range of possible decision thresholds is summarised by the area under the curve by a single number. The advantage of ROC is that it evaluates the ability of the score over the entire range of decision thresholds and hence is a complement to the measures of sensitivity and specificity. An area of 1.0 indicates a perfect ability to discriminate while an area of 0.5 indicates that the score performs no better than chance in discriminating between groups. Areas under the curve of less than 0.5 are considered to have poor discrimination; those between 0.7 and 0.9 , with moderately good discrimination; and values greater than 0.9 , excellent discrimination. ${ }^{23-25}$ The area under the curve for Ganga hospital score was 0.998 ( \pm 0.002 SEM) and Mangled Extremity Severity score was $0.988( \pm 0.008 \mathrm{SEM})$ and for Gustilo classification was 0.76 ( $\pm 0.57 \mathrm{SEM})$. An ROC curve was con- 
Table VI. Outcome of salvaged limbs in various groups of the Ganga hospital score

\begin{tabular}{llll}
\hline Outcome criteria & Group I (n= 23) & Group II (n= 51) & Group III* (n = 28) \\
\hline Mean (range) in-patient stay in days & $10.1(8$ to 15$)$ & $23.4(7$ to 65$)$ & 61 (16 to 140) \\
Mean (range) time to union in wks & $16(10$ to 28$)$ & $25(8$ to 55$)$ & $47(20$ to 110$)$ \\
Deep infection rate (\%) & $4.3(\mathrm{n}=1)$ & $13.7(\mathrm{n}=7)$ & $39.2(\mathrm{n}=11)$ \\
Number of flaps (\%) & $1(4.3)$ & $31(60.7)$ & $28(100)$ \\
Number of surgical procedures & 1 & 3 & 6 \\
Number of amputations & 0 & 0 & 1 \\
* includes only salvaged limbs & & &
\end{tabular}

Table VII. Wound cover procedures according to the Ganga hospital score skin score

\begin{tabular}{lllccc}
\hline Skin score & Skin suturing & Skin graft & Free flap & Local flap & Total \\
\hline 1 & 10 & 0 & 0 & 0 & 10 \\
2 & 25 & 0 & 1 & 1 & 27 \\
3 & 0 & 5 & 0 & 2 & 7 \\
4 & 0 & 2 & 17 & 38 & 57 \\
5 & 0 & 0 & 0 & 1 & 1 \\
Total & 35 & 7 & 18 & 42 & 102 \\
\hline
\end{tabular}

structed for the 67 type-IIIB injuries. The area under the curve for Ganga hospital score was 0.988 ( \pm 0.013 SEM), for Mangled Extremity Severity score was 0.938 ( \pm 0.039 SEM) and for Gustilo classification was 0.5 ( \pm 0.122 SEM). It is seen that the Ganga hospital score was more predictable and with lesser standard error than the Mangled Extremity Severity score. Also, Gustilo's classification had no predictive value in the question of salvage as it has the lowest possible area under the curve.

Outcome measures. Since all limbs in group IV had an amputation, the requirement for plastic surgery, the total number of in-patient days, the number of surgical procedures required before the completion of treatment, the time to bony union and rate of infection were studied only in the other three groups (Table VI).

Requirement for plastic surgery. Of the 102 injuries salvaged, 42 required simple wound management with primary closure or a split-skin graft and the remaining 60 a flap procedure, of which 42 were local and 18 free flaps (Table VII). In group I, only one of the 23 required a local flap. However, 31 of the $51(60.7 \%)$ group-II injuries required a flap, of which seven were free flaps. All of the 28 group-III injuries needed a flap of which 11 were free flaps.

The requirement for a specialised plastic surgery procedure was well predicted by the score for skin and covering tissues. All injuries with a score of one, and 25 of 27 $(92.6 \%)$ with a score of two were managed by skin suture. Only two $(7.4 \%)$ required a flap because of loss of skin and soft tissue during secondary debridement. One of these injuries was in the lower one-third and hence a free flap was preferred. By contrast, of the 57 injuries with a score of four, $17(29.8 \%)$ required a free flap, $38(66.6 \%)$ a local flap and only two $(3.5 \%)$ could be managed by a skin graft. The requirement and complexity of flap for the Ganga hospital score groups by univariate analysis of variance
(ANOVA) were highly significant $(\mathrm{p}<0.0001)$. A skin score of three and above demands plastic surgical attention as soon as possible.

In-patient days. The mean number of in-patient days in group I was 10.1 (8 to 15 ) compared with 23.4 (7 to 65 ) in group II and 61 (16 to 140 ) in group III. Patients in group I had only one admission compared with a mean of 2.1 (1 to 3 ) in group II and of 3.2 (2 to 5 ) in group III.

Number of surgical procedures. The mean number of surgical procedures required for group I was only one, compared with three in group II and six in group III $(\mathrm{p}<$ $0.0001)$. All the procedures in group I and $86 \%$ (133) of those in group II were carried out during the primary admission, whereas $57 \%$ (101) of those in group III were performed during subsequent admissions.

Time to bony union. The time to bony union, the number of secondary procedures required to achieve union and the need for bone grafting correlated well with the skeletal score. The mean time to union was 17 weeks for injuries that scored one, 29 weeks for those scored two and three, 31 in those scored four and 52 for a score of five. Similarly, bone grafting was required in none with a score of one, in two of 11 patients with a score of two and in 19 of 37 patients with a score of three. While none of the patients with a score of three or below required bone transport, seven of 12 with a score of four and all of the 14 salvaged limbs with a score of five required limb reconstruction with bone transport. The difference between these groups was significant $(\mathrm{p}<0.001)$. Injuries with a score of one $(28)$ required no secondary bony procedures to achieve union compared with two of $11(18.1 \%)$ patients with a score of two, 19 of $37(51.4 \%)$ with a score of three, all of the 12 with a score of four and all of the 14 salvaged patients with a score of five.

Rate of infection. Wounds were considered to be infected if they had leakage for more than a week or required antibiotics for wound healing. Infection occurred in 27 of the 102 salvaged limbs $(26.5 \%)$, of which eight $(7.8 \%)$ were superficial and $19(18.6 \%)$ were deep. Only one of 23 of group I $(4.3 \%)$, ten of $51(19.6 \%)$ in group II and 16 of 28 $(57.1 \%)$ of group III had infection. Considering only deep infections, one of 23 of group I $(4.3 \%)$, seven of 51 $(13.7 \%)$ in group II and 11 of $28(39.2 \%)$ in group III had infections. The difference between group I and group II, and between group II and group III was significant (chisquared test; $\mathrm{p}<0.001)$. 


\section{Discussion}

Systems of classification of fracture and injury severity scores have been developed to guide the surgeon in making appropriate decisions. ${ }^{26}$ The Gustilo-Anderson classification, ${ }^{1,2}$ which is the most widely-used, has several disadvantages and has undergone many modifications since its original description. Differing interpretations by various authors have resulted in loss of uniformity in its global application. . $^{3,6-11}$ Type-IIIB includes a wide spectrum of injuries from the easily manageable to the barely salvageable and is therefore unable to provide guidelines for management or allow comparison of published results from different institutions. In the 67 type-IIIB injuries included in our study there was a wide scatter among the various groups of the Ganga hospital score and the Mangled Extremity Severity score, indicating the variety of injuries classified as type-IIIB.

The Gustilo classification is based more on the nature and size of the wound and does not address specifically the severity of injuries of the musculotendinous structures and skeletal structures.${ }^{6,7}$ Injury to the muscles, nerves and bone can often be more crucial than the nature of the wound. The system also does not consider comorbid factors and does not address the question of salvage. There is a high degree of subjectivity leading to poor inter-observer reliability. ${ }^{3,6-9}$ Two major studies evaluating the Gustilo classification have reported a low inter-observer agreement rate of about $60 \%$, which varied with the experience of the surgeon and the type of injury. ${ }^{8,9}$ This classification is not an adequate basis for making decisions concerning treatment or for comparison of published results. A more detailed, accurate and objective method for the assessment of typeIII injuries is needed. . $^{3,5-10}$

Our experience of treating more than 300 open injuries to the lower limb every year prompted us to evolve a score which assessed separately the severity of the injury to each component of the limb as well as the overall damage. Other factors which influence the decision to salvage the limb were included by provision of a comorbid score. The score underwent two clinical trials and suitable modifications to its present form.

The first decision in the management of a severely injured lower limb is the question of salvage. While it would be a disaster to amputate a salvageable limb, failed reconstructions leading to secondary amputations are unacceptable and frustrating to the patient..$^{27,28}$

Many injury severity scores for the lower limb have been developed, the more important of which are the Mangled Extremity Severity score; ${ }^{12}$ the limb salvage index $;^{15}$ the predictive salvage index; ${ }^{13}$ the nerve injury, ischaemia, soft-tissue injury, skeletal injury, shock and age of patient (NISSA) score ${ }^{14}$ and the Hannover fracture scale-97. ${ }^{16,17}$ These scores, however, have been designed to assess limbs with combined orthopaedic and vascular injuries and are poor predictors for type-IIIB injuries. ${ }^{18}$ Retrospective design, small sample sizes and a clinical bias of the score designers in the selection of components and weighting of the indices have been quoted as the other serious flaws. ${ }^{29-31}$ A prospective evaluation of their clinical use found that they performed poorly when applied to typeIIIB injuries in which vascularity was not a problem. ${ }^{18}$ They are not easily applied and therefore have not been regularly used in clinical practice. There is a need for a single scoring system which has a high sensitivity and specificity for salvage in type-IIIB injuries and which can predict clinical outcome.

The Mangled Extremity Severity score, although originally designed to address limbs with combined vascular and orthopaedic injuries, ${ }^{12}$ has also been widely used in evaluating those with normal perfusion. ${ }^{18}$ It was developed retrospectively and then validated prospectively with a small sample size. A score of seven or more was reported to be $100 \%$ predictive of amputation. However, it has not been duplicated in other prospective series in which an overall rate of sensitivity of $46 \%$, increasing to $72 \%$ when only ischaemic limbs are considered, has been reported. ${ }^{18,29-31}$ Our experience with this score has been the same. We found a high sensitivity of $99 \%$ and a positive predictive value of $97.5 \%$ indicating that it may be useful in predicting limbs which should not undergo amputation, but the specificity was only $17 \%$ with a negative predictive value of $50 \%$, indicating that a large proportion of limbs eventually requiring amputation would be at risk of a delay in this procedure. In our series, of the seven patients who had an amputation, four had a score of below seven, proving the unreliability of the Mangled Extremity Severity score in evaluating type-IIIB injuries in which vascularity is not compromised.

By contrast, the Ganga hospital score was found to have a high sensitivity and specificity when a score of 14 was chosen as the threshold for amputation. In predicting amputation, it would be ideal if the sensitivity, namely the probability that limbs requiring amputation will have the scores at or above the index threshold was $100 \%$ and the specificity, the probability that limbs which can be salvaged will have limb-salvage scores below the threshold was also $100 \% .{ }^{18}$ However, few scores could achieve this in clinical situations, particularly with open injuries. It is better to err on the side of high specificity so that only a negligible number of salvageable limbs would score above the amputation threshold score, but a high sensitivity rate is also essential in order to decrease the number of secondary amputations. The specificity for a threshold score of 14 was $100 \%$, which decreased to $83 \%$ for a score of 15 and $67 \%$ for a score of 16 . We therefore set a threshold score of 14 . All the 89 patients with or below a score of 14 by the Ganga hospital score were salvaged. In contrast, one of the three patients with a score of 15 , one of the two with a score of 16 , both with a score of 17 and all three patients with 18 underwent amputation. Of the seven patients who had amputation only five had a primary amputation. Two underwent secondary amputation later and both had a 
score of 18. Application of the Ganga hospital score would have avoided this.

It is advisable that injuries with a score of 14 and below should have attempts at salvage, those with a score of 17 and above should be considered for primary amputation, and those in between assessed by an experienced team on a case-by-case basis. It is important to have an intermediate 'grey zone' rather than a single threshold score since there are many other influencing factors such as the expertise of the treating team, the social and cultural background of the patient, the cost and the personality of the patient.

In our series, the only significant independent variable to predict salvage was the Ganga hospital score $(\mathrm{p}=0.03)$ and the findings of both the Mangled Extremity Severity score $(\mathrm{p}=0.09)$ and the Gustilo score $(\mathrm{p}=0.9)$ were not significant.

The Ganga hospital score accurately predicted the need for soft-tissue cover and also the requirement for complex flap procedures (Table VII). Of the salvaged limbs, the mean covering tissue score of the 42 patients who did not require a plastic surgical procedure was two, compared with four in the 60 patients who required a flap procedure $(p<0.001)$. All the 39 patients except two $(94.9 \%)$ with a score of less than three had primary skin closure or skin grafting whereas 58 of $63(92 \%)$ patients with a score of three or above required flap cover $(\mathrm{p}<0.001)$.

The practical use of this classification is clear. The availability of plastic surgical services at the same hospital as an orthopaedic service is not universal even in developed countries and is at a premium in many developing parts of the world. Injuries with a soft-tissue score of three and above must be immediately transported to a centre where softtissue cover may be undertaken.

The functional tissue score was designed to record the extent of damage to the muscles and posterior tibial nerve, whether the injury involved either a part or an entire compartment and whether the damage could be repaired without functional loss. In many open injuries the damage to the muscles can be less unless there is a crush element. Of the 109 patients in our study, 79 had a score of one or two. Higher scores influenced the outcome significantly since all patients with a score of five finally underwent amputation.

The Mangled Extremity Severity, NISSA, and Hannover fracture scale-97 scores are heavily influenced by the results of the initial neurological examination. ${ }^{12,14,16}$ This can be misleading since sensory impairment may be present in an acute injury due to temporary ischaemia, contusion or traction. There may be full recovery later. ${ }^{32}$ The limb salvage index assesses the neurological deficit on the basis of anatomical nerve findings. ${ }^{15}$ The NISSA score added a nerveinjury component with the highest weight given to an insensate sole. It has been suggested that a complete posterior tibial nerve injury is a definitive indication for amputation. ${ }^{14}$ However, we feel that even the presence of complete irreparable damage to the posterior tibial nerve should not be an indication for amputation. Surgeons in the developing world are well aware that patients with Hansen's disease who have complete loss of plantar sensation of both feet can be successfully rehabilitated. The ability to have the functional use of the lower limb in spite of severe injury of the posterior tibial nerve in other conditions, such as in tumour surgery, has been well documented. ${ }^{32,33}$ In our experience some patients with a complete posterior tibial nerve injury can lead a normal life and hence the importance of a nerve injury was reduced to three in the Ganga hospital score.

The skeletal score was useful in predicting the time to bony union and also the nature of the reconstruction required. Injuries with a score of two and less, irrespective of the covering tissues score, were found to have a high rate of union without the need for bone grafting. Injuries with a bony score of four and five had a lengthy time to union and required additional surgical procedures. The number of patients requiring bone transport also correlated well with the score with all 14 injuries with a score of five needing this.

The incidence of deep infection was $4.3 \%$ in group I, $13.7 \%$ in group II and $39.2 \%$ in group III. The increase in the rate of infection with the increase in total score was notable and significantly different in the groups. There was a high rate of infection in group III in our series. The patients in group III had severe injuries to both bone and soft-tissue, many required multiple reconstructive procedures. The rate of infection was higher in these complex cases.

The Ganga hospital score is of practical value in helping the surgeon to make appropriate decisions and forecast the outcome. It has higher sensitivity and specificity for predicting amputation, even when vascularity is not affected, than the presently available lower-limb injury severity scores. It is superior to the modified Gustilo classification of type-III injuries since it addresses the question of salvage and also provides a more accurate assessment of the injury to the limb. It has a better inter-observer agreement rate and is practical for routine clinical use. Although it has been validated in our centre, multicentre trials will be required next to evaluate its effectiveness.

\section{Supplementary Material}

A further opinion by $\mathrm{Mr}$ Charles Court-Brown is available with the electronic version of this article on our website at www.jbjs.org.uk

We would like to thank Mr N. Arunkumar, Bio-statistician, for his advice and help regarding statistical analysis.

No benefits in any form have been received or will be received from a com mercial party related directly or indirectly to the subject of this article.

\section{References}

1. Gustilo RB, Anderson JT. Prevention of infection in the treatment of one thousand and twenty-five open fractures of long bones: retrospective and prospective analysis. J Bone Joint Surg [Am] 1976;58-A:453-8.

2. Gustilo RB, Mendoza RM, Williams DN. Problems in the management of type II (severe) open fractures: a new classification of type III open fractures. J Trauma 1984; 24:742-6. 
3. OIson SA. Open fractures of the tibial shaft: current treatment. Instr Course Lect 1997;46:293-302.

4. Gustilo RB. Interobserver agreement in the classification of open fractures of the tibia: the results of a survey of two hundred and forty-five orthopaedic surgeons. J Bone Joint Surg [Am] 1995;77-A:1291-2.

5. Brumback RJ, Jones AL. Reply to the letter. J Bone Joint Surg [Am] 1995;77-A: 1292.

6. Rockwood CA, Green SP. Fractures in adults.Vol 1, Fourth ed. Philadelphia: Lippincott-Raven, 1996:309-11.

7. Chapman MW. The role of intramedullary fixation in open fractures. Clin Orthop 1986;212:26-34.

8. Brumback RJ, Jones AL. Interobserver agreement in the classification of open fractures of the tibia: the results of a survey of two hundred and forty-five orthopaedic surgeons. J Bone Joint Surg [Am] 1994;76-A:1162-6.

9. Horn BD, Rettig ME. Interobserver reliability in the Gustilo and Anderson classification of open fractures. J Orthop Trauma 1993;7:357-60.

10. DeLong WG Jr, Born CT, Wei SY, et al. Aggressive treatment of 119 open fracture wounds. J Trauma 1999;46:1049-54.

11. Sanders R, Swiontkowski M, Nunley J, Spiegel P. The management of fractures with soft tissue disruptions. J Bone Joint Surg [Am] 1993;75-A:778-89.

12. Helfet DL, Howey T, Sanders R, Johansen K. Limb salvage versus amputation: preliminary results of the Mangled Extremity Severity score. Clin Orthop 1990;256: 80-6.

13. Howe HR Jr, Poole GV Jr, Hansen KJ, et al. Salvage of lower extremities following combined orthopedic and vascular trauma: a predictive salvage index. Am Surg 1987; $53: 205-8$

14. McNamara MG, Heckman JD, Corley EG. Severe open fractures of the lower extremity: a retrospective evaluation of the Mangled Extremity Severity Score (MESS). J Orthop Trauma 1994:8:81-7.

15. Russell WL, Sailors DM, Whittle TB, Fisher DF Jr, Burns RP. Limb salvage versus traumatic amputation: a decision based on a seven-part predictive index. Ann Surg 1991;213:473-81.

16. Seekamp A, Kontopp H, Tscherne H. Hannover Fracture Scale ‘98: reevaluation and new prospects for an established score system. Unfallchirurg 2001;104:601-10 (in German).

17. Tscherne H, Oestern HJ. A new classification of soft-tissue damage in open and closed fractures (author's transl). Unfallheilkunde 1982;85:111-15.
18. Bosse MJ, MacKenzie EJ, Kellam JF, et al. A prospective evaluation of the clinical utility of the lower-extremity injury severity scores. J Bone Joint Surg [Am]2001; 83-A:3-14.

19. Baker SP, O'Neill B, Haddon W Jr, Long WB. The Injury Severity Score: a method for describing patients with mulitple injuries and evaluating emergency care. J Trauma 1974; 14:187-96

20. Greenfield ML, Kuhn JE, Wojtys EM. A statistics primer: validity and reliability. Am J Sports Med 1998;26:483-5.

21. Portney LG, Watkins MP, eds. Foundations of clinical research: applications to practice. 2nd ed. Upper Saddle River NJ: Prentice-Hall Inc; 2000.

22. Zweig MH, Campbell G. Receiver-operating characteristic (ROC) plots: a fundamental evaluation tool in clinical medicine. Clin Chem 1993;39:561-77.

23. McDowell I, Newall C. Measuring health: a guide to rating scales and questionnaires. 2nd ed. New York: Oxford University Press; 1996:32.

24. Swets JA. Measuring the accuracy of diagnostics systems. Science 1988;240: 1285-93.

25. DeLong ER, DeLong DM, Clarke-Pearson DL. Comparing the areas under two or more correlated reciever operating characteristic curves: a nonparametric approach. Biometrics 1988;44:837-45.

26. Burstein AH. Fracture classification systems: do they work and are they useful? J Bone Joint Surg [Am] 1993;75-A:1743-4.

27. Bondurant FJ, Cotler HB, Buckle R, Miller-Crotchett P, Browner BD. The medical and economical impact of severely injured lower extremities. J Trauma 1988;28: 1270-3.

28. Hansen ST Jr. The Type-IIIC tibial fracture: salvage or amputation. J Bone Joint Surg [Am] 1987;69-A:799-800.

29. Bonanni F, Rhodes M, Lucke JF. The futility of predictive scoring of mangled lower extremitites. J Trauma 1993;34:99-104.

30. Durham RM, Mistry BM, Mazuski JE, Shapiro M, Jacobs D. Outcome and utility of scoring systems in the management of the mangled extremity. Am J Surg 1996; 172:569-74.

31. Lange RH. Limb reconstruction versus amputation decision making in massive lower extremity trauma. Clin Orthop 1989;243:92-9.

32. Bosse MJ, McCarthy ML, Jones AL, et al. The insensate food following severe lower extremity trauma: an indication for amputation? J Bone Joint Surg [Am] 2005; 87-A:2601-8

33. Brooks Ad, Gold JS, Graham D et al. Resection of the sciatic, peroneal, or tibial nerves: assessment of functional status. Ann Surg Oncol 2002;9:41-7. 